\title{
AVANCES INTERNACIONALES DE LOS TEMAS DE PROPIEDAD INTELECTUAL EN BIOTECNOLOGÍA*
}

Joseph Straus **

\section{SUMARIO}

I. La iniciativa de la OECD. - II. Avances internacionales subsiguientes; i) General; ii) El trabajo de la OMPI; iii) Los esfuerzos de revisión de la UPOV y su resultado; iv) Proyecto de legislación de la Comisión de la Comunidad Europea; a) Propuesta para una Directiva del Consejo respecto a la protección legal de los inventos biotecnologicos; b) Propuesta para una regulación de la Comunidad sobre derechos de variedad de plantas. - III. La práctica de las oficinas de patentes. - IV. La Convención de Biodiversidad; i) Propiedad intelectual y recursos genéticos; ii) El contenido de la Convención; iii) Puntos principales de crítica; a) La posición de los EE.UU.; b) Puntos de vista europeos; c) La Convención de Biodiversidad: ¿una desventaja para la protección de los inventos biotecnológicos?.- V. Perspectivas.

\section{La iniciativa de la OECD}

El Análisis internacional sobre biotecnología y protección de patente ${ }^{1}$ de la OECD***, de 1985, marcó el comienzo de las discusiones internacionales

* Traducido del inglés por Antonio Luya Cierto.

** Dr. jur. Profesor de Leyes, Facultad de Leyes, University of Ljubljana, Profesor Visitante de Leyes, Escuela de Leyes de Cornell, Cornell University, Ithaca, N. Y.; Jefe de Departamento, Max-Plack Institute for Foreign and International Patent, Copyright, and Competition Law, Munich.

*** Organización de Cooperación y Desarrollo Económico.

1 Beier, Crespi y Straus, Biotechnology and Patent Protection. An International Review, OECD, París, 1985. 
respecto a temas de propiedad intelectual en la biotecnología moderna. Mayormente basado en respuestas oficiales de 19 de 24 países miembros a un cuestionario, este análisis ofreció información de primera mano respecto a los casos legales y la práctica administrativa en los respectivos países. El grupo de expertos de la OECD ha percibido diferencias considerables en las leyes nacionales pertinentes y ha enfatizado la necesidad generalizada de una armonización internacional. Específicamente recomendó inter alia: la introducción de un período de gracia a nivel internacional, el cual permitiría al inventor publicar sus descubrimientos científicos sin perder automáticamente la posibilidad de una subsiguiente solicitud de patente; facultar peticiones dirigidas a organismos; aceptar el depósito de microorganismos en una colección de cultivos reconocida, como una alternativa o un medio complementario de protección contra la revelación y la repetición del invento; mejorar la posición del depositante-solicitante con respecto a la publicación de microorganismos por uno u otro posponiendo la revelación al público hasta la concesión de patente, o por la introducción de un sistema de acceso limitado del público hasta el material depositado entre la publicación de la solicitud y la concesión de la patente, por ejemplo, la «solución experta», como se conoce bajo la Convención Europea de Patentes (EPC); y buscar soluciones para dar una protección más efectiva a plantas nuevas surgidas de métodos de ingeniería genética, preferentemente permitiendo al innovador la alternativa de escoger el tipo de protección más apropiado que le asegure una compensación justa por su inversión, por ejemplo, la alternativa entre patentes y derechos especiales de reproductor de acuerdo a los lineamientos de la Convención de la UPOV. Constituyó un asunto de la mayor preocupación para el grupo, que semejante alternativa no estuviera permitida bajo los reglamentos de la UPOV y que la situación, además, se agravara por las estipulaciones de las leyes de patentes de los países europeos y de la EPC, las que expresamente han excluido de la protección de patente a las variedades de plantas o animales y esencialmente a los procedimientos biológicos para la producción de plantas o animales².

2 Ver las «Specific Recommendations» en las páginas 90 ss. 


\section{Avances internacionales subsiguientes}

\section{i) General}

Los avances científicos y legales que siguieron a la publicación del informe OECD pueden resumirse como sigue:

La ingeniería genética y otras modernas técnicas de la biotecnología, tales como por ejemplo la técnica de la hybridoma para la producción de anticuerpos monoclonales, han producido resultados notables en el campo farmacéutico, así como en el campo de la reproducción de plantas y animales. Los científicos de este campo inventaron numerosos métodos nuevos para la manipulación de material biológico, así como productos nuevos tales como secuencias-DNA, -genes- compilaciones para proteínas útiles, constructores de genes, plásmidos, anticuerpos monoclonales, líneas celulares, cultivos de tejidos, plantas y animales transgenéticos. Los científicos solicitaron protección vía las patentes de invención y pusieron a prueba a las oficinas respectivas, las que tuvieron que enfrentar este problema.

Estos desarrollos fueron paralelos a los esfuerzos combinados de la Organización Mundial de la Propiedad Intelectual (OMPI), la Unión Internacional para la Protección de Variedades Nuevas de Plantas (UPOV) y la Comisión de las Comunidades Europeas, dirigidos a considerar las sugerencias del grupo OECD, cada una dentro del ámbito de su competencia. Aunque el objetivo global de estas actividades fue el establecimiento de mejores pautas de protección para los inventos biotecnológicos, los objetivos concretos diferían considerablemente: mientras que, desde un comienzo, la OMPI se limitó a brindar algún apoyo para sus países miembros con el fin de promover la armonización en el campo legislativo, la UPOV dedicaba sus esfuerzos a enmendar la Convención. La Comisión de la Comunidad Europea, por su parte, dirigía sus esfuerzos a armonizar la protección de patente para los inventos biotecnológicos en sus Estados miembros mediante una Directiva, e introduciendo derechos sobre la reproducción de plantas a través de un reglamento.

\section{ii) El trabajo de la OMPI}

Un Comité de Expertos en Inventos Biotecnologicos y Propiedad Industrial 
trató este tema entre los años 1984 y 1987. La OMPI encargó un conjunto de estudios ${ }^{3}$ y envio dos cuestionarios a los gobiernos y organizaciones intergubernamentales, así como a organizaciones no gubernamentales . El resultado de estos esfuerzos fue un informe compuesto de tres partes; la primera parte trata la situación existente con respecto a la disponibilidad y alcances de la protección para los inventos biotecnológicos y el sistema de depósito de microorganismos; la segunda resume las sugerencias para mejoras según organizaciones no gubernamentales; y la tercera parte contiene diecinueve soluciones sugeridas preparadas por la Oficina Internacional, concernientes a la protección como propiedad industrial de las invenciones biotecnológicas ${ }^{4}$.

Las soluciones sugeridas fueron diseñadas en relación a dos aspectos principales: por un lado, fueron influenciadas por el hecho de que las leyes nacionales y la EPC han excluido de la protección de patente a ciertos inventos biotecnológicos, tales como variedades de plantas o animales, esencialmente procedimientos biologicos para la producción de animales y plantas, así como métodos de diagnóstico o quirúrgicos practicados en el cuerpo de un animal ${ }^{5}$. Por otro lado, surgió la necesidad de dar orientación legislativa a la administración y a los tribunales con respecto a temas aún no resueltos por la jurisprudencia pero considerados como particularmente esenciales, por ejemplo, los temas de: cómo cumplir con el requisito de permitir la revelación de datos, incluyendo temas de requisitos de depósito y los efectos del depósito ${ }^{6}$; cómo trazar la línea divisoria entre descubrimientos no patentables e inventos, en lo referente a material preexistente; cómo esta-

${ }^{3}$ Cf., por ejemplo, Straus, «La protección de las invenciones biotecnológicas por la propiedad industrial. Análisis de ciertas cuestiones básicas», OMPI Doc. BIG 281, Ginebra 1985 (1986).

4 Ver WIPO Reports, «On Industrial Property Protection of Biotechnological Inventions», Industrial Property, 1986, p. 252 ss., y «On the Third Session of The Committee of Experts on Biotechnological Inventions and Industrial Property», Industrial Property, 1988, p. 104 ss.

5 Artículos 53 (b) y 52 (4) EPC. Para detalles sobre estas exclusiones, ver Moufang, «Protection for Plant Breeding and Plant Varieties. A Frontier of Patent Law», 23 IIC, 328 ss. (1992).

- Sobre estos temas generalmente ver, Straus y Moufang, Deposit and Release of Biological Material for the Purposes of Patent Procedure. Industrial and Tangible Property Issues, Baden-Baden, 1990. 
blecer el alcance de la protección del procedimiento de patente con respecto a productos que consisten en materia viviente y el de patentes de productos relacionados con información genética. Tomando en cuenta la creciente complejidad de las relaciones entre los resultados de la reproducción tradicional de plantas, que seguirían comprendidos bajo la protección de la UPOV, y los inventos modernos de plantas biotecnológicas, que también podrían estar considerados bajo la protección de una patente, la Oficina Internacional sugirió una licencia de dependencia sobre patentes dominantes, las que bajo ciertas condiciones podrían concederse a los reproductores. La tendencia general de las soluciones sugeridas por la OMPI era asegurar la aplicación más limitada o literal posible de las disposiciones excluyentes de la ley de patentes y permitir una interpretación de las leyes de patentes que adecuadamente considerara las peculiaridades y las necesidades especiales de los inventos biotecnológicos y de sus creadores. La meritoria labor de la OMPI fue bien recibida por la mayoría de los Estados miembros y por los círculos no gubernamentales interesados. En vista de las diferencias existentes en las leyes de patentes nacionales, sin embargo, las soluciones sugeridas nunca han sido formalmente adoptadas ni por el Comité de Expertos ni por ninguna otra institución de la Unión de París. Un remanente importante de estos esfuerzos puede encontrarse en el Proyecto de Tratado Complementario de la Convención de París en lo que concierne a Patentes?. Este Proyecto fue negociado por primera vez en una Conferencia Diplomática en La Haya en junio de 1991 y se continuará en una segunda Conferencia Diplomática programada para julio de 1993. El Proyecto ofrece básicamente dos alternativas en lo que se refiere a la protección de inventos biotecnologicos: o imponer la protección de patente para inventos de productos y procedimientos en todo campo tecnológico, o permitir a los Estados contratantes mantener o introducir estipulaciones excluyentes en lo que se refiere a inventos biotécnicos dentro de los lineamientos de la $\mathrm{EPC}^{8}$. En vista de que esta estipulación será discutida sólo en la segunda parte de la Conferencia Diplomática de julio de 1993, por ahora las reacciones de los Estados participantes son difíciles de prever?.

7 WIPO Doc. PLT/DC/3 de 21 de diciembre de 1990.

8 Artículo 10. «Fields of Technology».

- Además, el artículo 12 del Proyecto estipula un período general de gracia de doce meses para el registro o fecha de prioridad en lo que respecta a las revelaciones propias de los inventores. El tema del periodo de gracia, sin embargo, ha llegado a 
El mérito esencial de los esfuerzos de la OMPI se apreciará en un mejor entendimiento de los problemas en el derecho de patentes, que han surgido con el desarrollo de la biotecnología moderna. Aunque todavía no ha habido una reacción positiva de los Estados miembros de la Unión de París, tanto entes administrativos como tribunales de justicia han adquirido un conocimiento considerable del tema. El resultado más concreto de las soluciones sugeridas, sin embargo, fue el hecho de que constituyeron la base y el punto de partida para la iniciativa legislativa de la Comisión de la Comunidad Europea en la adopción de una Directiva sobre la protección legal de inventos biotecnológicos ${ }^{10}$.

\section{iii) Los esfuerzos de revisión de la UPOV y su resultado}

Desde el comienzo de las discusiones internacionales, la UPOV ha observado de cerca el impacto de la biotecnología sobre la filosofía básica que sustenta la Convención de la UPOV. El primer resultado fue condensado en un estudio titulado «La protección de las variedades de plantas y el debate sobre inventos biotecnologicos», el que fue presentado en $1985^{\prime \prime}$. El motivo principal de la preocupación de la UPOV fue la práctica emergente en algunas oficinas de patentes, que empezaron a otorgar patentes para inventos de plantas. Inicialmente, en 1983, la Junta Técnica de Apelación de la Oficina de Patentes Europea aclaró que bajo el artículo 53 (b) EPC sólo el patentamiento de plantas o su materia de propagación en la forma genética de una variedad de planta, pero no de plantas en general, eran excluidos de la protección de patente ${ }^{12}$. Posteriormente, en 1987, la Oficina de Patentes y Marcas de los EE.UU. (PTO) otorg6 una patente en la cual una semilla de maíz con un contenido endógeno libre de tryptofano fue solicitada expresamente.

ser parte de un complejo paquete de negociación, abarcando la cuestión esencial del primero en registrar o el primero en inventar, el debate principal. Está aún por verse si ello podría resolverse en la segunda parte de la Conferencia Diplomática. Sobre el controversial debate de la armonización, en los EE.UU., cf. Moy, «Essay: Patent Harmonization, Protectionism, and Legislation», 74 JPTOS 777-810; y Banner, «Fleecing the Golden Fleece», 74 JPTOS 811-821.

10 Ver infra, iv) a).

11 UPOV Doc. INF/11 de 10 de diciembre de 1985.

12 Decisión del 26 de julio de 1983, OJ EPO 1984, 12. «Propagating Material CIBA/GEIGY». 
Además, la PTO aceptó el depósito de semillas como parte del permiso de revelación ${ }^{13}$.

El trabajo de revisión de la Convención de la UPOV comenzó en 1986/1987 y fue terminado en marzo de 1991 con la adopción de una nueva Acta revisada. En el curso de controvertidos debates que precedieron la adopción del Acta revisada, dos líneas importantes de argumentos se enfrentaban: por un lado, el deseo de proteger el predominio o la exclusividad del tipo de protección de la UPOV en el campo de las plantas y variedades de plantas para contrarrestar los avances en la práctica del otorgamiento de patentes; por otro lado, la necesidad de modernizar y mejorar el sistema para adaptarse no sólo a la nueva situación resultante de la aplicación de la moderna biotecnología en las plantas sino también para superar las antiguas y tradicionales insuficiencias y defectos del sistema. La versión revisada que fue adoptada ${ }^{14}$ debe ser considerada como un compromiso. Sin embargo, este compromiso ha reforzado significativamente el tipo UPOV de protección de la variedad de planta y ha abierto el camino para una verdadera coexistencia de patentes y derechos de reproductores de plantas.

Los cambios más importantes en la nueva Acta pueden resumirse como sigue: la prohibición de la doble protección, es decir, se ha desechado por completo la posibilidad de proteger las variedades de plantas mediante patentes y derechos de reproductores ${ }^{15}$. Las partes contratantes, bajo la nueva Acta, después de un período de transición de cinco años contados a partir de su sujeción a ella, deben extender protección a todo género y especie de planta, como una protección permitida por la presente Acta. El principio de

${ }^{13} \mathrm{~N}^{\circ} 4,642,411$, de 10 de febrero de 1987. «Hibberd y et al». Cf. también Adler, «Can Patents Coexist with Breeeders' Rights? Developments in U.S. and International Biotechnology Law», 17 IIC, p. 195 ss. (1986).

${ }^{14}$ Convención Internacional para la Protección de Variedades Nuevas de Plantas, de 2 de diciembre de 1969, revisada en Ginebra el 10 de noviembre de 1972, el 23 de octubre de 1978 y el 19 de marzo de 1991, UPOV Doc. DC/91/138 de 19 de marzo de 1991. Ver también UPOV (ed.), Records of the Diplomatic Conference for the Revision of the International Convention for the Protection of New Varieties of Plants, Geneva, 1991, Ginebra 1992.

${ }^{15}$ En este punto ver Straus, «Patent Protection for New Varieties of Plants Produced by Genetic Engineering. Should "Double Protection" Be Probibited», 15 $I I C$, p. 426 ss. (1984). 
trato nacional ya no estaría limitado por un tratamiento de reciprocidad ${ }^{16}$. El margen de protección ha sido considerablemente ampliado y ahora, bajo condiciones específicas, puede incluir también materiales cosechados, incluyendo plantas enteras y partes de plantas e inclusive ciertos productos elaborados directamente de material cosechado de la variedad protegida ${ }^{17}$. Al ampliar el margen de protección a las variedades derivadas esencialmente de la variedad protegida, el principio de independencia, conocido como «privilegio del reproductor», ha experimentado limitaciones considerables ${ }^{18}$. Observaciones del mismo tipo pueden hacerse con respecto al privilegio del agricultor, es decir, a su derecho de resembrar semillas rescatadas de su propia cosecha. Aunque esta exención aún se mantiene, explícitamente se le llama una «exención opcional», la que las partes contratantes pueden estipu-

${ }^{16}$ Comparar la crítica sobre estos puntos débiles de la UPOV en Straus: «The Relationship Between Plant Variety Protection and Patent Protection for Biotechnological Inventions from an International Viewpoint», $18 I / C$, p. 723 ss. (1987).

${ }^{17}$ Bajo el presente artículo 5 (1) del Acta de la UPOV en la versión revisada de 1978, el campo de protección está limitado a la producción comercial y el mercadeo del material de propagación, como tal, de la variedad protegida; así, no cubre la comercialización de los productos finales, por ejemplo, ni frutos, hojas, raíces, etc., ni semillas vendidas para siembra y subsiguiente producción en una cosecha de trigo a ser vendida para convertirla en harina. Las nuevas reglas de la UPOV contenidas en el artículo 14 superan la regulación actual, pero son realmente complicadas: por un lado, la regla general del artículo 14 (1) estipula que la producción o la reproducción (multiplicación) (i), el acondicionamiento para propósito de propagación (ii), el ofrecimiento para venta (iii), la venta u otro tipo de comercialización (iv), la exportación (v), la importación (vi) y el almacenamiento para estos propósitos (vii), del material de propagación, están reservados para el reproductor. Por otro lado, los reproductores de plantas extienden sus derechos al material cosechado, incluyendo plantas enteras y partes de plantas, únicamente si fueron obtenidas por uso no autorizado del material de propagación y sólo a menos que el reproductor haya tenido oportunidad razonable para ejercer su derecho en relación a dicho material de propagación. No debería haber duda de que los legisladores nacionales tendrán dificultades considerables cuando transformen estas estipulacones en leyes nacionales. Para más detalles, ver Byrne, Commentary on the Substantive Law of the 1991 UPOV Convention, Londres, 1992, p. 49 ss.

${ }^{18}$ Sobre el problema de dependencia ver Straus, "The Principle of "Dependence" under Patents and Plant Breeders' Rights", Industrial Property, 1987, p. 433 ss. 
lar sólo dentro de límites razonables y sujeta a la salvaguardia de los intereses legítimos del reproductor ${ }^{19}$.

Si los inventores y la industria involucrados en biotecnología de plantas se beneficiarán a cabalidad de las mejoras en la Convención de la UPOV, una vez que el Acta revisada entre en vigencia, ello dependerá eventualmente de la prontitud con que los legisladores del derecho de patentes eliminen las estipulaciones que excluyen las variedades de plantas de la protección de patente. También será de importancia esencial determinar si, y cómo, la definición de «variedad» de planta, que ha sido introducida en la nueva Acta de la UPOV ${ }^{20}$, influenciará la práctica de las oficinas de patentes y la jurisprudencia en las decisiones sobre las estipulaciones excluyentes. Sin considerar todas las mejoras de la Convención de la UPOV, empero, se deberá tomar siempre en cuenta que un certificado de variedad de planta, sin importar cuán grande sea su margen de protección, se relaciona sólo con una variedad específica, por lo que no puede ofrecer protección adecuada para avances tecnológicos genéricos en biotecnología ${ }^{21}$.

\section{iv) Proyecto de legislación de la Comunidad Europea ${ }^{22}$}

\section{a) Propuesta para una Directiva del Consejo respecto a la pro- tección legal de los inventos biotecnológicos}

Como se indic 6 anteriormente, las soluciones sugeridas presentadas por la

19 También la transformación de esta disposición en leyes nacionales se espera que cause grandes controversias. Cf. Byrne, op. cit., nota al pie 17, p. 61 ss.

${ }^{20} \mathrm{De}$ acuerdo al artículo 1 (vi) «variedad» significa un agrupamiento de plantas en un taxón botánico particular del menor orden conocido, el que, con independencia de si las condiciones para la concesión de un derecho de reproductor están completamente reunidas, puede ser definido por la expresión de las características resultantes de un genotipo dado o de una combinación de genotipos, distinguido de cualquier otro agrupamiento de plantas por la expresión de al menos una de dichas características, y considerado como una unidad con respecto a su propiedad para ser propagada inalterable. Así, ni una planta particular ni una o varias partes de una planta, por ejemplo, células, granos, cultivos de tejidos, etc., cumplirán este criterio.

21 Ver Crespi, «Patents and Plant Variety Rights: Is there an Interface Problem?», 23 IIC, p. 168 ss. (182 s.) (1992).

${ }^{22}$ Para los aspectos europeos específicos de la protección de los inventos 
Oficina Internacional de la OMPI constituyeron el punto de partida para la iniciativa de la Comisión de la Comunidad Europea. El proposito principal de la propuesta para una Directiva del Consejo respecto a la protección legal de los inventos biotecnológicos, que la Comisión presentó en octubre de 1988 , fue $^{23}$ : «establecer, armonizar, aclarar y mejorar los patrones de protección de los inventos biotecnológicos para promover un completo potencial innovador y la competitividad de la ciencia e industria de la Comunidad en este importante campo de la tecnología ${ }^{24}$. A pesar de estos ambiciosos objetivos, la propuesta se mantuvo con firmeza dentro de los términos de la Convención de la UPOV, y respetó las estipulaciones excluyentes de la EPC.

Específicamente, se tratan cuestiones esenciales como: la patentibilidad de la materia viva, los efectos de la exclusión de patentabilidad de variedades de plantas y animales, el alcance de la protección de la patente para la materia viva y la revelación suficiente, incluyendo todos los aspectos del depósito y salida de material biológico. Respecto a la patentabilidad de la materia viva, la intención general de la propuesta es la de asegurar una interpretación restrictiva de todas las estipulaciones excluyentes en todos los Estados miembros. En otras palabras, garantizar la elegibilidad de microorganismos, animales y plantas y partes de ellos, siempre y cuando las variedades de plantas y animales como tales no estén en peligro ${ }^{25}$. En vista de la prohibición de patente para ciertos inventos - la publicación o explotación de los cuales serían contrarias al orden público o la moral, como está dispuesto en todas las leyes nacionales o por los Estados miembros en el artículo 53(a) de la EPC-, la Comisión opinó que era completamente claro que el cuerpo humano y sus partes, como tales, jamás serían elegibles para ninguna clase de protección de patente. Por este motivo la propuesta ha guardado silencio sobre este tema delicado. En lo que respecta al ámbito de protección, las estipulaciones pertinentes de la propuesta se dirigen a ase-

biotecnológicos, ver Bercovitz, «Problemática de la protección de las invenciones biotecnologicas desde una perspectiva europea», en: Biotecnología y patentes, Revista del Derecho Industrial, No 34 , enero-abril de 1990, pp. 55 a 84.

${ }^{23}$ «Propuesta para una Directiva del Consejo sobre la protección legal de los inventos biotecnológicos», Doc. COM (88) 496 final. SYN 159, del 17 de octubre de 1988.

${ }^{24}$ Memorándum explicativo, parte uno, No. 8.

${ }^{25}$ Artículos 2-5. 
gurar los legítimos intereses del inventor del procedimiento, no sólo en lo que respecta a la primera generación de productos de su procedimiento patentado sino también con respecto a generaciones subsiguientes. Por lo tanto, la propuesta considera las peculiaridades de la materia viva cạpaz de autorreproducirse. El inventor de un producto que contenga información genética especial goza de protección, la que se extiende a algunos productos en los que dicha información haya sido incorporada y permanezca como de importancia esencial ${ }^{26}$. Mediante una estipulación especial, que ha definido el agotamiento del derecho de patente después de que el producto patentado ha ingresado al mercado, se ha aclarado que no debería haber privilegio del agricultor bajo las leyes de patente ${ }^{27}$. Aparte de proponer un sistema mejorado para depósito, acceso y redepósito de material biologico ${ }^{28}$, la propuesta también contiene una estipulación de licencia de dependencia sobre patentes dominantes en favor de los poseedores de derechos de reproductor de plantas, en casos en los que la variedad protegida represente un progreso técnico significativo $0^{29}$.

Las consultas subsiguientes respecto a la propuesta en el Consejo de Ministros y en el Parlamento Europeo han resultado muy difíciles. Como una pelota de ping pong, la propuesta pasaba de uno a otro de estos organismos y a los diferentes comités del Parlamento Europeo. La controversia se ha concentrado principalmente en las dimensiones éticas de los inventos biotecnológicos y en los impactos de los derechos exclusivos sobre agricultura $^{30}$. En octubre de 1992, el Parlamento Europeo aprobó en conjunto 46 enmiendas $^{31}$, las cuales, de ser adoptadas en su totalidad por el Consejo de

${ }_{26}$ Artículos $12-13$.
${ }_{27}$ Artículo 11.
${ }_{28}$ Artículos 15-16.
Artículo 14. Para mayores detalles sobre esta propuesta, ver Bergel, «El proyecto de directiva europea relativo a la protección jurídica de invenciones biotecnológicas», en: Biotecnología y patentes, Revista del Derecho Industrial, N $^{\circ} 34$, eneroabril, 1990, pp. 85 - 105

${ }^{30}$ Cf., por ejemplo, Sesión del Parlamento Europeo de 29 de enero de 1992, PE 150. 463/final, Informe del Comité sobre Asuntos Legales y Derechos de los Ciudadanos (Informante: Sr. W. Rothley).

31 Ver Documentos de la Sesión del Parlamento Europeo, de 5 de octubre de 1992, PE 201.664/final, y de 29 de octubre de 1992, PE 161.995-PV 34 II. 
Ministros, representarían un obstáculo significativo para la protección de los inventos biotecnológicos en la Comunidad Europea en relación al estado actual. Desde que, sin embargo, la Comisión en su enmendada «Propuesta de diciembre de $1992 »^{32}$ ha considerado las enmiendas propuestas por el Parlamento sólo hasta cierto límite, sólo debiera hacerse mención de los cambios esenciales introducidos por la Comisión en su propuesta original.

En lo que respecta a los aspectos éticos, la Comisión ha admitido en principio que la simple referencia a las estipulaciones de las leyes de patentes existentes acerca de la exclusión de protección de inventos que están en conflicto con la moral y el orden público, no da la importancia ni asume la complejidad y la nueva dimensión proveniente de los inventos biotecnologicos. Consecuentemente, los temas éticos están ahora incorporados en las obligatorias «cláusulas considerando que» y en el artículo 2 (3) de la propuesta. La última estipulación no sólo repite la conocida «cláusula etica» general de las leyes de patentes, sino que especifica que el cuerpo humano y sus partes (a); los procedimientos para modificar la identidad genética del cuerpo humano para un propósito no terapeutico, lo que es contrario a la dignidad del hombre (b); así como los procedimientos para modificar la identidad genética de animales, probablemente causando sufrimiento o impedimentos físicos en ellos sin ningún beneficio para el hombre o el animal (c), no son elegibles para protección de patente. Refieriéndonos al debate en el «Parlamento Europeo», en el Memorándum Explicativo la Comisión ha aclarado que como «partes del cuerpo humano» deben ser entendidas sólo aquellas partes que están dentro del cuerpo humano. El artículo 2 (3) por lo tanto de ningún modo excluye de la protección de patente asuntos por los que ya se había otorgado patentes anteriormente por la Oficina Europea de Patentes (EPO), tales como una línea celular humana del tipo linfoblastoides ${ }^{33}$, la molécula DNA capaz de provocar la expresión de un anfitrión unicelular de un polipéptido que muestre la actividad biológica o inmunológica del interferón humano tipo beta ${ }^{34}$, un procedimiento de cultivo humano hepatocito ${ }^{35}$, la manipulación clónica molecular y la caracterización

32 «Propuesta Revisada para una Directiva del Consejo sobre la Protección Legal de Inventos Biotecnológicos», Doc. COM (92) 589 — final- SYN 159 de diciembre de 1992.

${ }^{33}$ EP No. 0113.769 B1 de 15 de febrero de 1989.

34 EP No. 0041.313 B1 de 12 de setiembre de 1990.

${ }^{35}$ EP No. 0143.809 B1 de 18 de enero de 1989. 
de una secuencia genética codificada para relaxina humana ${ }^{36}$, etc. Por otro lado, el Memorándum sostiene que, por ejemplo, las secuencias de genes humanos con funciones aún no establecidas no podían ser patentables ${ }^{37}$. Cabe mencionar que de acuerdo al Memorándum Explicativo los métodos para una terapia somática de genes, si no son practicados en el cuerpo humano, son en principio elegibles para una protección de patente. De acuerdo a la Comisión queda abierta la posibilidad de otorgar protección legal para inventos capaces de mejorar considerablemente la existencia humana afectada por la enfermedad. Sin embargo, la terapia «germinal» de genes, esto es, la alteración de células de germen, que podría llevar a cambios genéticos capaces de transmitirse a la prole, al menos por el momento, caería bajo las estipulaciones excluyentes. Siendo el motivo principal el hecho de que esta terapia está aún en la etapa de experimentación en cultivos de células humanas y animales ${ }^{38}$.

Aparte del hecho de que el tema ético ha sido tratado en forma tan específica por primera vez en la historia del derecho de patentes, la terminología de la propuesta enmendada parece concordar con las opiniones tradicionalmente expresadas en la doctrina legal y los principios básicos que han regulado la protección de patentes desde sus comienzos. Esto, sin embargo, no es cierto para la segunda enmienda esencial de la propuesta hecha por la Comisión, a saber, la inclusión de un «privilegio del agricultor» en el artículo 13. Si se adoptase, esta estipulación permitiría a los agricultores emplear semillas guardadas (de plantas patentadas) de su cosecha, exento de costo alguno para subsiguiente multiplicacion generativa o vegetativa en la producción agrícola del respectivo agricultor. Además, permitiría a los agricultores multiplicar animales patentados en sus propias granjas a fin de renovar su ganado. La introducción del privilegio del agricultor es claramente una

${ }^{36}$ EP No. 0101.309 B1 de 16 de setiembre de 1991.

${ }^{37} \mathrm{El} \mathrm{Memorándum} \mathrm{explicativo} \mathrm{expresa} \mathrm{literalmente:} \mathrm{«Se} \mathrm{sobreentiende} \mathrm{que,} \mathrm{si} \mathrm{el}$ solicitante solamente desea patentar una simple parte del "cuerpo humano" per se, por ejemplo, un gene humano, ni su función ni la proteína por la que su código es conocido será patentable» (op. cit. p.7).

${ }^{38}$ Memorándum explicativo, p. 8. Para Alemania, debería añadirse que esta clase de terapia está prohibida por la ley actual, desde que el Acta de protección del Embrión Humano de 13 de diciembre de 1990 expresamente prohíbe cualquier manipulación de células de gérmenes humanos (cf. Straus, «Biotechnologische Erfindungen - ihr Schutz und Seine Grenzen», GRUR 1992, p. 252 ss. (261)). 
infracción de todos los principios tradicionales que rigen el derecho de patentes y un compromiso de último minuto entre la Comisión y el Parlamento Europeo. La Comisión, que ha rechazado constantemente esta propuesta anteriormente, está totalmente consciente del problema. Observando los avances en el campo de los derechos de los reproductores de plantas de la Comunidad, manifiesta en el Memorándum que el privilegio del agricultor en la ley de patentes no puede estipular limitaciones de derechos de patente que irían más allá de las limitaciones eventualmente estipuladas por el esquema de los derechos del reproductor de plantas ${ }^{39}$. En vista de la necesidad específica de la agricultura de la Comunidad Europea, de comercializar nuevos productos, incluso la un tanto limitada aproximación de la Comisión en este contexto es macroeconómicamente más que cuestionable. Dejando de lado el hecho de que actualmente no existe "privilegio del agriculton» en las áreas económicamente más importantes ${ }^{40}$ de las plantas híbridas, tales como el maíz, la betarraga, etc., las que todavía no han originado inconveniente alguno sino que, al contrario, han dado un largo período de prosperidad en sus áreas de producción, el instituto del privilegio del agricultor obviamente distraerá a la industria biotécnica de las inversiones necesarias en investigación agrícola y la llevará a concentrarse en la investigación y el avance de híbridos ${ }^{41}$.

39 A este respecto, el Memorándum explicativo dice: «La Comisión está totalmente consciente, sin embargo, de que el privilegio del agricultor no debe hacer posible, bajo la ley de patentes, que lo que está prohibido bajo la ley de protección de la variedad de planta, resultante en ciertas áreas de la agricultura o la horticultura, tales como las plantas ornamentales, árboles frutales o vides, resulte afectado. Por eso ha rechazado la enmienda oral añadida por el Comité de asuntos legales del Parlamento con el propósito de insertar la expresión "u otro material propagable" después de la primera mención de la palabra "semilla". Así, en cuanto a lo que concierne a la Comisión, "semilla" debe ser entendido en un sentido limitado». (op. cit., p. 17).

40. Debido a la infertilidad de las semillas cosechadas.

41 Debe llamarse la atención sobre el hecho de que, en la actualidad, por ejemplo en Alemania, el costo de semillas por hectárea es de entre 150 y 200 marcos alemanes, pero la porción de regalías por semilla certificada es sólo de 8 a 15 marcos alemanes. Los costos por productos químicos - herbicidas, pesticidas, etc. - van al mismo tiempo de 320 a 420 marcos alemanes, y los «costos de regulación de mercado», por ejemplo subsidios, llegan a alrededor de 1000 marcos alemanes (ver Straus, GRUR, 1992, p. 265, con referencias adicionales). Para el privilegio del agricultor relacionado con los problemas bajo el Acta de los EE.UU. sobre Protección de Va- 
Para el resto de la propuesta enmendada, se puede observar que la terminología ha sido significativamente simplificada sin cambiar la substancia de la propuesta original. La única mejora notoria que cabe mencionar aquí, considera la estipulación del artículo 15 sobre depósito, acceso y redepósito de material biológico para propósitos de procedimientos patentados. Aquí la propuesta enmendada sigue las sugerencias hechas por el autor, como la llamada solución experta, que ahora estaría al alcance del depositante incluso después de que una solicitud haya sido rechazada, retirada, o esté considerándose su retiro, o después de que una patente haya sido anulada ${ }^{42}$.

\section{b) Propuesta para una regulación de la Comunidad sobre dere- chos de variedad de plantas}

Mientras que en el campo de las patentes los esfuerzos de la Comisión están dirigidos a la armonización de las leyes de patente nacionales, en el campo de los derechos de variedad de plantas la Comisión ha considerado el establecimiento de un derecho de variedad de plantas de la Comunidad, correspondiente a la patente de la Comunidad. La propuesta, presentada por la Comisión en agosto de $1990^{43}$, por lo tanto, contiene estipulaciones que regulan todos los aspectos de un sistema semejante, en particular el derecho substantivo, los efectos del nuevo derecho, el procedimiento de otorgamiento así como la organización del sistema. El artículo 1 señala que el Sistema de Derechos de Variedad de Plantas de la Comunidad, tal como está establecido bajo la regulación, es «la única y exclusiva forma de derechos de propiedad industrial para variedades de plantas resultantes de descubrimien-

riedades de Plantas (PVPA), ver la decisión de la Corte de Distrito de los EE.UU. para el distrito norteño de lowa, de 30 de setiembre de 1991 y 14 de noviemore de 1991, 69 Plant Variety Protection (publicación de la UPOV) 51 (1992). La corte recalcó que el término «semilla salvada» debería estar limitado a la cantidad de la semilla protegida requerida razonablemente por el agricultor que la produjo, para sembrar el número de acres de la variedad protegida, o su progenie, que él o ella necesite para la cosecha del año siguiente (loc. cit., p. 56). Esta limitación, sin embargo, en la práctica es rara vez observada.

42 Ver para detalles, Straus/Moufang, op. cit. p. 152 ss.

43 «Propuesta para una regulación del Consejo (EEC) respecto de los derechos de variedad de plantas de la Comunidad», Doc. COM (90) 347 final, de 30 de agosto de 1990 . 
to o reproducción». Además, el artículo 89 prohíbe la protección acumulativa, es decir, las variedades sujetas a los derechos de variedad de plantas de la Comunidad no serán patentadas ni serán materia de los derechos nacionales de variedad de plantas. Todos los derechos otorgados en contra de estas estipulaciones, serán ineficaces.

Considerando el hecho de que esta propuesta fue presentada por la Comisión antes de la adopción del Acta revisada de la UPOV, no sorprende que sus estipulaciones no estén del todo conformes con esa Acta y por tanto requiera de algunos ajustes. Resulta dudoso que la discusión actual en el Consejo de Ministros eventualmente resulte en la prórroga de la prohibición de la doble protección. Así aparece del hecho de que las estipulaciones excluyentes de la ley de patentes están apoyadas en la propuesta enmendada para la Directiva Biotécnica.

\section{La práctica de las oficinas de patentes}

Contrario al engorroso proceso de formulación, modificación o creación legislativa, las oficinas de patentes, puestas a prueba por numerosas solicitudes en todos los campos de la biotecnología, tuvieron que actuar con presteza. En aplicación de las reglas básicas desarrolladas por la Corte Suprema de los EE.UU. en el caso «Chakrabarty» ${ }^{44}$, de 1980, la Oficina de Patentes y Marcas de los EE. UU. (PTO) otorgó numerosas patentes no sólo para todas las clases de material biologico, tales como secuencias de genes, virus, líneas celulares, anticuerpos monoclonales, sino que también, con el caso «Hibberd ${ }^{45}$, comenzó a otorgar patentes para plantas y eventualmente para animales. En 1987, la PTO, en la decisión «ex parte Allen», anunció que «las ocurrencias no naturales de organismos vivos multicelulares no humanos, incluyendo animales», eran consideradas materia patentable dentro de los alcances de 35 U.S.C. $\S 101$, pero rehusaron la solicitud debido a su falta de inventiva ${ }^{46}$. La primera patente para un animal transgenético, el «ratón Harvard», fue otorgada por la PTO el 12 de abril de $1988^{47}$. Desde el pri-

44 Decisión de 16 de junio de 1980, 206 USPQ 193-197 (en Diamond v. Chakrabarty).

45227 USPQ 443 (Ex parte Hibberd).

462 USPQ 2d 1425 (Ex parte Allen).

47 US Patent $N^{\circ} 4,736,966$. La declaración 1 se refiere a: «Un mamífero 
mer anuncio por la PTO sobre patentamiento de animales, un número de proyectos de ley dirigidos a imponer una moratoria en el patentamiento de animales o a limitar los efectos de las patentes de animales con respecto a los agricultores (por ejemplo, el «Acta de Reforma de Patente de Animal Transgenético» de setiembre de 1988, o los proyectos de ley del senador Hatfield de Oregon, de febrero de 1990 y junio de 1991) han sido presentados al Congreso de los EEUU. Sin embargo, ninguno de los proyectos fue aprobado ${ }^{48}$. A mediados de 1992 unas 145 solicitudes de patentes referidas a nuevas formas de vida animal estaban pendientes ante la PTO, la que en diciembre de 1992 otorgo tres patentes adicionales para ratones ${ }^{49}$.

La Oficina de Patentes Europea (EPO) también siguió el ejemplo y otorgó, en los mismos rubros que la PTO, numerosas patentes para todas las clases de material biologico ${ }^{50}$. Bajo la doctrina de la decisión «CIBAGEIGY ${ }^{51}$, se otorgaron las primeras patentes para plantas y para los procedimientos de su producción $\mathrm{n}^{52}$ y eventualmente, el 3 de abril de 1992, también para el «ratón Harvard» ${ }^{53}$. La orientación que el Consejo Técnico de Apelaciones de la EPO ha ofrecido en su decisión sobre el caso «ratón Harvard» en $1990^{54}$, sobre la aplicación general de la «cláusula ética» del

transgenético no humano cuyas células germinales y células somáticas contienen un recombinante activado de una secuencia oncógena, introducido en dicho mamífero, o en un antepasado del mismo, en una etapa embrionaria. Las dependientes declaraciones 11 y 12 cubren al mamífero de la declaración 1, indicando que el mamífero es un roedor o ratón, respectivamente.

48 Para todos estos desarrollos, cf. Delevie, «Animal Patenting; Probing the Limits of U.S. Patent Laws», 74 JPTOS $492-509$ (1992), con referencias adicionales.

49 Cf. el Informe PTO sobre el tema de tres patentes para ratones genéticamente estructurados, 45 PTCJ 159 (1993).

50 Ver, por ejemplo, las patentes referidas en las notas de pie 32 a 35 . Observar, sin embargo, que las patentes han sido otorgadas en el EPO también para genes humanos codificados por Erythropoietin (EPO) - EP N 0144448605 B 1 y también para un factor estimulante de una colonia de Granulocitos (GCSF), EP N ${ }^{\circ} 0237545$ B1.

51 Decision de 26 de julio de 1983, OJ EPO 1984, 112 - Propagatin Material / CIBA-GEIGY.

52 Decisión de 10 de noviembre de 1988, OJ EPO 1990, 71 - Hybrid Plants / LUBRIZOL.

53 EP N 0169672 B 1, OJ EPO 1992, 589 - Onco-mouse / -HARVARD.

54 Decisión de 3 de octubre de 1990, OJ EPO 1990, 476. 
artículo 53 (a) y la estipulación excluyente del artículo 53 (b) de la EPC. ${ }^{55}$, es de importancia notable y ciertamente ha influenciado igualmente la redacción enmendada de la propuesta de Directiva de la EC.

Además de la continua controversia sobre temas éticos en relación con el patentamiento de plantas y particularmente de animales, las oficinas de patentes actualmente enfrentan un nuevo problema, a saber, solicitudes referidas a extensiones de DNA con posiblemente funciones aún no conocidas. La primera solicitud conocida de este tipo fue presentada por los Institutos Nacionales de Salud (NIH) en junio de $1991^{56}$. Esta solicitud, que revela 3421 secuencias que contienen un total de 724,837 nucleotides, ha ocasionado largas discusiones sobre patentamiento de genes no s6́lo entre aquellos que generalmente se oponen al patentamiento en el campo de las materias vivas, sino también en todo el público en general y en la comunidad científica internacional que está envuelta en «mapping» de genes y coopera con el Proyecto del Genoma Humano. Aunque la decisión preliminar de la PTO, de diciembre de 1992, rechazó la mayoría de las peticiones sobre la base de la falta de utilidad o novedad, la discusión continúa ${ }^{57}$. La Oficina de Evaluación de Tecnología (OTA) del Congreso de los EE.UU. está a punto de llevar a cabo una evaluación de «El Proyecto del Genoma Humano y el Patentamiento de las Secuencias de DNA Humanas». Igualmente, la Organización del Genoma Humano, de Europa, ha discutido cuidadosamente este tema en un taller de trabajo celebrado en noviembre de 1992. Los resultados de ese taller serán publicados pronto ${ }^{58}$. Al presente, parece que la opinión que ha sido expresada por la Comisión de la Comunidad Europea en el

55 Ver, detalles para, Straus, «Ethische, rechtliche und wirtschaftliche Probleme des Patent - und Sortenschutzes für die biotechnologische Tierzüchtung und Tierproduktion», GRUR Int. 1990, 913-928.

56 Cf. Roberts, «Genome Patent Fight Erupts», 254 Science 184-186 (1991); igual «NIH Gene Patents, Round Two», 255 Science 912-913 (1992). La NIH PCTaplication fue publicada el 1 de enero de 1933, Publication $\mathrm{N}^{\circ}$ WO 93/00353.

57 Ver, por ejemplo, Adler, «Genome Research: Fulfilling the Public's Expectations for Knowledge and Commercialization», 257 Sciencie 908-914 (1992); Kiley, «Patents on Random Complementary DNA Fragments?», 257 Science 915 918 (1992); Maebius, «Novel DNA Sequences and the Utility Requirent: the Human Genome Initiative», 74 JPTOS 651-658:

58 Cf. Galloway, «Intellectual Property in Genome Mapping Programmes» (Informe preparado para HUGO), próximamente en Nature. 
Memorándum Explicativo sobre la Propuesta Enmendada para la Directiva Biotecnologica, esto es, que las extensiones de DNA de funciones aún no conocidas no serían elegibles para protección de patente, representaría el actual punto de vista prevaleciente a nivel internacional.

\section{La Convención de Biodiversidad}

\section{i) Propiedad intelectual y recursos genéticos}

Cuando el 5 de junio de 1992, en Río de Janeiro, representantes de más de 150 países firmaron la Convención sobre Diversidad Biologica (Convención), contrariamente a algunas expectativas optimistas no se puso punto final a la larga y duradera controversia entre el Norte y el Sur respecto al acceso, explotación y preservación de los recursos genéticos del mundo ${ }^{59}$. En primer lugar, los EE.UU. rehusaron firmar la Convención. En seguida, un controversial debate sobre los potenciales impactos negativos de la Convención empezó entre el sector privado del mundo desarrollado y sus gobiernos. Considerando que la necesidad de proveer los medios efectivos e instrumentos para salvaguardar la diversidad biológica de la Tierra, que está principalmente concentrada en los trópicos ${ }^{60}$, no se cuestionaba por ningún lado, hay poco o ningún acuerdo en cuanto a la suficiencia de los medios empleados en la Convención dirigidos al logro de estos objetivos.

Antes de presentar brevemente el controvertido contenido de la Convención, parece necesario explicar por qué esta presentación es esencial en el contexto de este artículo. En otras palabras: explicar lo que los recursos genéticos y la biodiversidad tienen en común con la propiedad industrial, su protección y la moderna biotecnología en general, y específicamente dentro del contexto de la Convención. En relación al aspecto general, se ha obser-

59 Cf. sobre este debate, por ejemplo, Straus, «Plant Biotechnology, Industrial Property and Plant Genetic Resources», 21 Intellectual Property in Asia and the Pacific 21 ss., 44 s. (marzo-junio 1988); Correa, «Biological Resources and Intellectual Property Rights», 1992 EIPR 154-157 (154).

60 Parece ser un hecho que el ochenta por ciento de la biodiversidad terrestre de la Tierra probablemente se dé en los trópicos. Ver Raven/Wilson, «A Fifty Year Plan for Biodiversity Surveys», 258 Science 1099-1100 (1992). 
vado correctamente que los recursos genéticos representan una fuente de conocimientos ${ }^{61}$. Como fenotipos, es decir, como plantas y animales individuales, ellos tradicionalmente constituyen bienes particulares (corporeos). Como genotipos, es decir, como información incorporada en las constituciones genéticas de las especies de plantas y animales, ellos a priori se adecúan a la definición de bien público. Sin embargo, los genotipos pueden poseerse en exclusividad también ${ }^{62}$. Lo último es legítimo si el acceso a cllos estí limitado por cualquier poseedor o por los derechos de propiedad intelectual, tales como las patentes o los derechos de reproductor de plantas $^{63}$. Así, los avances, que llevaron al patentamiento de plantas y animales así como de microorganismos y otros materiales biológicos bajo las estipulaciones del derecho de patentes del mundo desarrollado ${ }^{64}$, han convertido a los potenciales recursos genéticos directa $o$, más probablemente, indirectamente, en materia sujeta a propiedad intelectual. Este cambio de situación está reflejado en nuevas formas de cooperación entre compañías y universidades interesadas en la búsqueda de productos químicos útiles farmacéuticamente, en plantas e insectos de los trópicos ${ }^{65}$ y en instituciones públicas o privadas de países que disponen de tales recursos genéticos. El mejor ejemplo conocido es el acuerdo concluido entre Merck \& Co. de los EE.UU. y el Instituto de Biodiversidad de Costa $R$, a (INBio). Se ha informado que Merck ha pagado un millón de dólares por el derecho de analizar plantas nativas y extractos de animales para utilizarlos en posibles fármacos

${ }^{61}$ Fisher: «Key Aspects of Species Extinction: Habitat Loss at Overexploitation», en Karrey Smith (ed.), Essays in Honor de John F. Krutilla, 1988, p. 59 (citado en Sedjo, «Property Rights, Genetic Resources and Biotechnological Change», XXXV (1) Journal of Law \& Economics 199-213 (200) (abril de 1992).

62 Cf. Sedjo, XXXV (1) Journal of Law \& Economics 201, 208 (abril de 1992).

${ }_{63}$ Debiera aclararse que el concepto de «variedad de planta» bajo la Convención de la UPOV es uno «inmaterial». El objeto protegido no son las semillas, retoños, cortes, brotes, etc., sino la información genética total decisiva para la nueva variedad de planta. Esta información es transferida a la prole por reproducción natural y es simplemente incorporada en el material de propagación concreto (tangible). Cf. Straus, Industrial Property, 1987, 434, nota al pie 10.

64 Ver supra III.

65 Ver para este tipo de investigación, Eisner, «Prospecting for Nature's Chemical Riches", Issues in Science and Technology 31 -34 (invierno 1989/1990); Tangley, «Cataloguing Costa Rica's Diversity», 40 BioScience 633-636 (octubre de 1990). 
u otros productos comerciales. En caso de que Merck descubra (invente) un producto comerciable basado en información obtenida, retendrá todos los derechos de patente, pero pagará a la INBio regalías que pueden fluctuar entre uno y tres por ciento. Diez por ciento del pago al contado y cincuenta por ciento de la parte de la INBio en regalías serán invertidos en conservación en Costa Rica ${ }^{66}$.

Por consiguiente, la Convención, cuyos objetivos son, de acuerdo al artículo 1,

«la conservación de la diversidad biológica, el uso sostenido de sus componentes y la justa y equitativa participación en los beneficios que surjan de la utilización de los recursos genéticos, incluyendo el acceso apropiado a los recursos genéticos y la apropiada transferencia de tecnologías relevantes, tomando en cuenta todos los derechos sobre aquellos recursos y tecnologías y el financiamiento apropiado»,

ha creado un nexo entre acceso «apropiado» y utilización de recursos genéticos, por un lado, y transferencia «apropiada» de tecnologías relevantes, incluyendo aquellas sujetas a patentes y otros derechos de propiedad intelectuàal, por otro.

\section{ii) El contenido de la Convención}

Para poder cumplir con los objetivos expresados en el artículo 1, la Convencion estipula una variedad de obligaciones y algunos derechos de las partes contratantes, es decir, de los Estados tanto del mundo en vías de desarrollo como del mundo desarrollado. Además, se ha ideado un «mecanismo de financiación» para la provisión de recursos financieros a los países partes en

66 Ver Stone, «The Biodiversity Treaty: Pandora's Box or Fair Deal?», 256 Science 1624 (1992). Ver también en el informe en 256 Science 1142 (1992), un acuerdo similar al de INBio, firmado el 25 de enero de 1992, con la Fundación de Investigación de Cornell, sin ningún pago al contado por la Universidad de Cornell. Además, la participación de los beneficios resultantes de la posible comercialización y también la propiedad de los derechos de propiedad intelectual, están diferentemente acordadas. 
vías de desarrollo, bajo la forma de una subvención o concesión (artículo 21). Una piedra angular de todo el sistema diseñado bajo la Convención debe verse en el reconocimiento explícito de los derechos soberanos de los Estados sobre sus recursos naturales, incluyendo su autoridad para determinar el acceso a los recursos genéticos a través de su legislación nacional (artículo 15 (1)). Así, no obstante la declaración del artículo 15 (2), de que

«cada parte contratante tratará de crear las condiciones para facilitar el acceso a sus recursos genéticos por parte de responsables y respetuosos usuarios del medio ambiente de otras partes contratantes y no impondrá restricciones reñidas con los objetivos de esta Convención»,

el fundamento para la propiedad exclusiva de los recursos genéticos sobre una escala internacional, ha sido establecido. El acceso a los recursos genéticos bajo el artículo $15(3,4$ y 5) requiere consentimiento previo y debe ser producto de condiciones acordadas mutuamente. Y el país que proporciona los recursos genéticos está autorizado para beneficiarse del uso comercial de éstos (artículo 15 (6)). Tal participación estará basada en condiciones acordadas mutuamente (artículo $15(7))^{67}$.

En cuanto al objetivo principal de la Convención, esto es, la conservación de la diversidad biológica, las obligaciones de las partes contratantes en lo que respecta a su identificación y seguimiento, como también a la conservación in situ y ex situ, están definidas de una manera muy vaga. La redacción de los artículos 7 al 9, que proveen numerosas medidas de conservación, sujeta las obligaciones respectivas de cada parte contratante a una limitación muy amplia y general: «en cuanto sea posible como apropiado».

Por otro lado, las obligaciones de las partes contratantes que se relacionan con el acceso y transferencia de tecnología, incluyendo biotecnología, como se establece en el artículo 16, parecen ser de considerable alcance y eventualmente podrían afectar el estado actual de los derechos de propiedad intelectual. De acuerdo a la regla general del artículo 16 (2), los

67 Ver Duesing, «The Convention on Biological Diversity, Its Impacts on Biotechnology Research», 3 AGRO Food Industry HITECH 1 - 9 (4) (julio/agosto de 1992). 
países en vías de desarrollo tendrán y/o se les facilitará el acceso y la transferencia de tecnología bajo condiciones justas y muy favorables, incluyendo términos de concesión y preferencia allí donde se haya acordado mutuamente. Si la tecnología patentada o protegida de otro modo estuviera en peligro, tal acceso y transferencia se otorgará en condiciones que reconozcan y sean consistentes con la adecuada y efectiva protección de los derechos de propiedad intelectual. Sin embargo, esta regla general tiene sus limitaciones. Primero, por la obligación de los países desarrollados, partes contratantes, de «tomar medidas legislativas, administrativas o políticas» para asegurar el acceso y la transferencia de tecnología protegida por patentes y otros derechos de propiedad intelectual en condiciones acordadas mutuamente, en particular para aquellos países en vías de desarrollo que proveen recursos genéticos (artículo 16 (3)) ${ }^{68}$. Segundo, y más importante aún, por la obligación de las partes contratantes de cooperar en el campo de las patentes y otros derechos de propiedad intelectual «sujetos a las leyes nacionales e internacionales, en orden a asegurar que tales derechos apoyen y no se opongan a sus [de la Convención] objetivos» (artículo 16 (5)).

La Convención, que contiene igualmente estipulaciones sobre temas tales como el establecimiento de un secretariado permanente (artículo 24), arreglo de disputas (artículo 27) y sobre sus enmiendas (artículo 29 ss.), entrará en vigencia noventa días después de la fecha de depósito del trigésimo instrumento de ratificación, aprobación o adhesión (artículo 36).

\section{iii) Puntos principales de crítica}

\section{a) La posición de los EE.UU.}

De acuerdo con un anuncio de prensa de la Oficina de Patentes y Marcas de los EE.UU. (U.S. PTO) de 22 junio de $1992^{69}$, hubo cuatro motivos princi-

68 De acuerdo al artículo 16 (4), tales medidas deberán ser tomadas también «con el objeto de que el sector privado facilite el acceso, desarrollo conjunto y transferencia de la tecnología referida en el párrafo 1 de arriba, para el beneficio de ambas instituciones de gobierno y el sector privado de los países en vías de desarrollo...».

69 «Questions and Answers. United States Position on the Convention on Biological Diversity». 
pales para que los EE.UU. no firmaran la Convención: el mecanismo de financiación era inaceptable; las obligaciones para transferir y dar acceso a la tecnología tomadas conjuntamente forzarían, más que alentarían, la transferencia de tecnología del sector privado de los EE.UU. hacia los países en vías de desarrollo que estuvieran fuera del sistema de libre mercado; se daba facultad para que los países restrinjan los derechos de propiedad intelectual habilitándolos para obtener y explotar tecnología de propiedad particular; los productos de la biotecnología por primera vez serían regulados de manera distinta que otros productos o prácticas que dañan el medio ambiente. Además, la U.S. PTO sostuvo que la Convención estaba pobremente redactada y que muchas de las obligaciones incorporadas en el tratado eran imprecisas.

Más específicamente, la U.S. PTO critica la «actitud paternalista» de la Convención, por la cual a los países en vías de desarrollo debería serles concedida la transferencia de (y el acceso a) la tecnología en condiciones justas y muy favorables, y no en condiciones definidas a través de las negociaciones en el libre mercado. Se ha observado que gracias a la soberanía reconocida sobre sus recursos genéticos, los países en vías de desarrollo, fuera de un lenguaje adicional en el tratado, deberían poder conseguir concesiones de las partes que requieren explotar sus recursos genéticos. Además, los EE.UU. deploran la ausencia de un compromiso de los países en vías de desarrollo para fomentar activamente la transferencia de tecnología, y de alguna obligación concreta para que un país respete los derechos del sector privado a la tecnología. En la opinión de los EE.UU. es inaceptable concordar con el principio de que es conveniente o necesario restringir los derechos de propiedad intelectual para fomentar la transferencia de tecnología del sector privado.

Los EE.UU., por lo tanto, sujetan la aprobación de esta Convención a:

- Eliminación o enmienda del artículo 16 (5) que otorga a las partes contratantes facultad para restringir o ignorar los derechos de propiedad intelectual;

- la aprobación del principio básico de que las condiciones de transferencia de tecnología, o de participación en actividades de investigación, deben ser aquellas en las que todas las partes involucradas estén completamente de acuerdo, lo que se obtiene únicamente a través del procedimiento de libre mercado. 
Adicionalmente, los EE.UU. han urgido firmemente a los países en vías de desarrollo para que tomen medidas para fomentar la inversión privada y el desarrollo

«significativamente, además de brindar protección adecuada y efectiva a los derechos de propiedad intelectual en la tecnología que resulta del desarrollo de los recursos genéticos» ${ }^{70}$.

\section{b) Puntos de vista europeos}

A diferencia de los EE.UU., los países europeos sí han suscrito la Convención. Sin embargo, las reacciones de la industria europea y sus asociaciones son predominantemente negativas. Aunque ha sido generalmente reconocido que bajo la Convención las obligaciones pueden establecerse sólo por las partes contratantes, es decir, por los gobiernos nacionales, la industria está principalmente preocupada por el hecho de que esta Convención podría llevar a una erosión esencial de los derechos de propiedad intelectual. La industria no se ha sentido satisfecha por la probabilidad de que los gobiernos europeos puedan ser de la opinión de que para la ratificación de la Convención no serían necesarios cambios en las leyes nacionales de propiedad intelectual. La posibilidad de que licencias obligatorias relativas a biotecnología pudieran ser introducidas en los países en vías de desarrollo en el futuro y a gran escala, es razón suficiente para oponerse a la ratificación del tratado.

Por otro lado, vale la pena destacar que, como ha sido expresado por la Comisión de Propiedad Industrial e Intelectual de la Cámara de Comercio Internacional,

«el mundo empresarial reconoce que los gobiernos nacionales ejercen soberanía al determinar el acceso a sus recursos naturales. Sin embargo, se opone a determinado tipo de fraseología que pudiera fomentar y autorizar la violación de los derechos de propiedad privada e interferir en las relaciones contractuales al

70 Ver también el informe «PTO, Biotech Group. Explains Objections to Earth's Biodiversity Treaty», 44 PTCJ 120-121 (noviembre de 1992). 
obligar compartir la información, tecnologías o know kow de fuentes privadas. Semejantes medidas gubernamentales crearían desincentivos para una potencial inversión extranjera en sus países» ${ }^{71}$.

Sin embargo, la idea de que la propiedad legal de recursos genéticos de plantas retenidos en los diecisiete mayores centros internacionales de investigación agrícola (integrantes del Grupo Consultivo sobre Trabajo de Investigación Internacional Agrícola (CGIR)), podría resultar de la Convención, constituye una gran preocupación para los reproductores de plantas. Como cerca de 600,000 muestras de plantas están almacenadas en los bancos de «geno-plasma» de estos centros, se temen obstáculos administrativos y cargas financieras adicionales ${ }^{72}$.

Es también interesante que los efectos del hecho de que los EE.UU. no hayan firmado la Convención, sean diferentemente interpretados por americanos y europeos. Mientras algunas voces de los EE.UU. han señalado que la industria biotecnologica norteamericana estará en desventaja porque el gobierno no firmó la Convención ${ }^{73}$, la industria europea manifiesta que su similar norteamericana será más competitiva en la adquisición de recursos genéticos porque su gobierno no estará obligado por la Convención. Hasta el momento, sólo John Duesing, de la División de Semillas de CIBAGEIGY, es cautelosamente optimista en la estimación de los efectos de la Convención. Sin embargo, también para Duesing la Convención de Biodiversidad sólo estará funcionando de una manera provechosa para todas las partes contratantes, si los derechos de propiedad intelectual sobre material biológico y genético se van a reconocer en todo el mundo, es decir, tanto en los países desarrollados como en los países en vías de desarrollo ${ }^{74}$.

71 Ver ICC Doc. $N^{\circ} 450 / 725 ; 210 / 417$ de 12 de octubre de 1992.

72 Cf. Madeley, «Summit hitch for plant breeders», Financial Times de 30 de junio de 1992.

73 Ver, por ejemplo, Stone, 256 Science, 1624 (1992); Reid, «Bush Biodiversity Policy Risks Dangerous Side Effects» The Wall Street Journal de 8 de octubre de 1992, p. A.15; Hackett, «No: A Competitive Disadvantage», ABA Journal 43 (setiembre de 1992).

74 Op. cit., p.8. 


\section{c) La Convención de Biodiversidad: ¿una desventaja para la protección de los inventos biotecnológicos?}

La crítica dirigida al vago y en muchos aspectos nada claro y ambiguo lenguaje de la Convención, es también compartida. Lo mismo es cierto para la crítica del esfuerzo general de la Convención para eventualmente alcanzar sus objetivos principalmente por medios administrativos. Esto, sin considerar el hecho de que tales medios podrían afectar en forma contraproducente a importantes instrumentos de la economía de mercado, tales como las patentes - en el caso de medidas concedidas a países en vías de desarrolloo podrían posiblemente estar en conflicto con derechos constitucionalmente garantizados del sector privado -en el caso de medidas requeridas desde los países desarrollados-. A despecho de la estipulación del artículo 16 (2), que rinde tributo a la importancia de los derechos de propiedad intelectual, especialmente el artículo 16 (5) podría en algún grado indicar un renacimiento de la obsoleta y ya abandonada filosofía de la Conferencia de las Naciones Unidas para el Comercio y el Desarrollo (UNCTAD) respecto al tratamiento de las patentes en los años setenta ${ }^{75}$. Esta actitud última, sin embargo, aparece no sólo insostenible para el mundo desarrollado, sino que, en vista de la experiencia anterior, sería también perjudicial para el destino de la Convención como tal ${ }^{76}$.

A despecho de todas estas deficiencias que pueden seriamente poner a prueba y cuestionar el destino último de la Convencion, en este momento parece prematuro rechazarla del todo. Deberíamos percatarnos de que bajo esta Convención, por primera vez, el principio de soberanía de los Estados sobre sus «recursos genéticos» ha sido establecido. En otras palabras, la an-

75 UNCTAD: The Role of the Patent System in the Transfer of Technology to Developing Countries, United Nations, New York, 1975. Sobre los efectos negativos de la doctrina de la UNCTAD para los países en vías de desarrollo, ver Straus, «Patent Protection in Developing Countries. An Overview», en Lesser et al., «Equitable Patent Protection for the Developing World», Cornell Agricultural Economics Staff Paper 89-36 (noviembre de 1989).

76 Se ha señalado correctamente que debido a una aproximación similar respecto a la transferencia de tecnología, la Convención de Derecho del Mar, relacionada con el uso de los recursos del lecho marino, ha fracasado completamente, y lo mismo podría suceder con la Convención de Biodiversidad. Ver Hathaway, «Yes: A Threat to Property Rights», ABA Journal 42 (setiembre de 1992). 
teriormente defendida doctrina del legado común de la humanidad, que en el pasado tuvo la consecuencia del uso libre de costo de, por ejemplo, las características específicas del maíz mejicano o de las especies de papa peruana ${ }^{77}$, ha sido abandonada. Considerando el hecho de que los recursos genéticos como «genotipos» representan información incorporada en la constitución genética de las especies de plantas y animales, además de otros materiales biológicos ${ }^{78}$, la cual no es sólo transferida a la prole sino que también es multiplicada «automáticamente» por el proceso de reproducción natural, deberíamos percatarnos, además, de que en la práctica la propiedad de los recursos genéticos puede proveer la compensación adecuada sólo por medio de las patentes y otros derechos de propiedad intelectual. Una vez que esta idea está completamente asumida por todos los involucrados, el problema esencial sólo puede ser cómo dar derechos de propiedad intelectual efectivos respecto a recursos genéticos per se y sus derivados. No limitaciones de los derechos de propiedad intelectual en biotecnología, sino más bien su establecimiento y mejoramiento, son necesarios en orden a hacer posible a los que, basados en recursos genéticos, desarrollan nuevas variedades de plantas o animales, productos farmacéuticos o químicos, el compartir sus beneficios con los propietarios de recursos genéticos, sobre la base de un acuerdo mutuo. El acuerdo Merck-INBio puede servir de ejemplo: sólo cuando Merck esté en posición de recibir protección de patente, por ejemplo, para un gene específico identificado y aislado de una planta tropical costarricense codificable por una glico-proteína, útil, por ejemplo, como fármaco anticáncer y como fármaco per se, Merck estará obligado y habilitado para pagar regalías a la INBio de Costa Rica. Esto sin decir que la suma final de regalías también dependerá del número de países en que Merck obtenga las patentes. En un aspecto, sin embargo, el acuerdo MerckINBio podría no ser el mejor ejemplo. Puesto que Costa Rica es un mercado pequeño, Merck probablemente no intentará producir el fármaco allí y podría inclusive proveer contienda contra productos no patentados o contar

77 Sedjo, XXXV (1) The Journal of Law and Economics 205 s. (1992). Aquel principio de que los recursos genéticos de plantas son una herencia de la humanidad y consecuentemente debieran estar disponibles sin restricciones, estuvo basado en el artículo 1 del «International Undertaking on Plant Genetic Resources», adoptado bajo los auspicios de la FAO en 1983. Cf. Lommi, «Problems Related to Legal Protection of Plants», 1989, NIR 1S.

78 Ver supra. 
con medidas administrativas de protección por parte del gobierno de Costa Rica. Por lo tanto, Merck podría no estar interesado en obtener protección de patente en Costa Rica para el gene y/o el fármaco. El conflicto de intereses sería ciertamente diferente en el caso de un país con un enorme mercado y también con recursos humanos propios en investigación y desarrollo. Podría adelantarse que a Merck le interesaría obtener la protección de patente para sus logros en orden a obtener una adecuada recompensa para su contribución también en ese país, y el país en cuestión esperaría a ver a Merck activo, si no en investigación y desarrollo, al menos en producción en el mismo país. Apenas puede ser cuestionado que la protección efectiva de los derechos de propiedad intelectual en biotecnología, en un país que dispone de recursos genéticos, facilitaría la conclusión de los respectivos acuerdos. Ello permitiría también al dueño de los recursos genéticos pedir más por el acceso a estos recursos.

En cuanto a la vigorosa crítica del artículo 16 (5) de la Convención, se debería tener en cuenta que, en la actualidad, en la mayor parte de países con ricos recursos genéticos, virtualmente no existe protección para los derechos de propiedad intelectual en biotecnología ${ }^{79}$. Curiosamente, la mayoría de aquellos países incluso no son miembros de la Convención de París: los únicos que hasta ahora permanecen ausentes de esta Convención están localizados en áreas de rica diversidad genética, como Bangladesh, India, Pakistán, Tailandia, Bolivia, Ecuador, Perú y Venezuela ${ }^{80}$. Las posibles res-

79 Esto es particularmente cierto para todos los países latinoamericanos, con la excepción de Argentina y México. Cf. Correa, «Patentes y Biotecnología: opciones para América Latina», en Biotecnología y patentes, Revista del Derecho Industrial, $N^{\circ} 34$, enero-abril de 1990 , p. $5-53$ (tablas en p. 48, 49); R.E. Evenson / D.D. Evenson/ -Putnam, «Private Sector Agricultural Invention in Developing Countries» en Ruttat/Pray (eds.), Policy for Agricultural Research, Boulder, 1987, p. 469-511 (tabla 19.1 en p. 482 ss.). Colombia, Ecuador y Perú en los años 1977, 1978 y 1979, por ejemplo, han incorporado la Decisión 85 del Acuerdo de Cartagena del Pacto Andino en sus leyes nacionales. Cf. Schwaiger, "Development and Current Problems of the Uniform Patent Law in the Andean Pact», 13 IIC 566-587 (1982). Sobre el estado último del derecho en los países andinos, también respecto al tratamiento especial de los inventos biotecnológicos, ver Kresalja, «La Decisión 313», THEMIS, Revista de Derecho, 1992, 23, p. 89-106 (92/93).

${ }^{80}$ Así, para las solicitudes de patentes presentadas en estos países, el derecho de prioridad del artículo 4 de la Convención de París no puede ser invocado. 
tricciones resultantes del artículo 16 (5) de la Convención pueden ser motivo de preocupaciones prácticas sólo en lo que respecta a un futuro lejano, esto es, sólo después de que la protección ha sido establecida. Por lo menos, esta estipulación podría influenciar negativamente futuros adelantos.

De lo anterior debería resultar que la Convención, si es aplicada adecuadamente, tiene potencial para, por primera vez, proveer mecanismos para una explotación exitosa de los recursos genéticos así como para una recompensa adecuada por el acceso a esos recursos. Sin embargo, en orden al logro de estos objetivos, la redacción de la Convención requiere de mejoras. El rechazo de los EE.UU., que, sin embargo, reconoce explícitamente la soberanía de los Estados sobre sus recursos genéticos, puede ser razón suficiente para adoptar bajo el artículo 28 un protocolo especial en lo que se refiere a derechos de propiedad intelectual. Teniendo en mente el nexo decisivo entre la propiedad de los recursos genéticos y los derechos de propiedad intelectual sobre aquellos recursos, así como sobre sus derivados, el protocolo debería estipular las obligaciones de todas las partes contratantes para establecer y respetar los derechos de propiedad intelectual cubriendo adecuadamente todos los inventos en biotecnología. En vista de la estipulación del artículo 5(A) de la Convención de París para la Protección de la Propiedad Intelectual, la estructura internacional para la protección de los derechos de propiedad intelectual ofrece suficientes posibilidades para introducir bajo las leyes nacionales suficientes y efectivas salvaguardias frente a abusos potenciales del monopolio de patente.

\section{Perspectivas}

Predecir el resultado de los avances presentados en este informe no es una tarea realista. Esto es igualmente cierto para el Proyecto de legislación de la Comunidad Europea, el Tratado de Armonización de la OMPI y la Convención de Biodiversidad. Sólo en el caso del Acta de 1991 de la UPOV, puede asumirse que entrará en vigencia a su debido tiempo para la mayoría de los Estados miembros de la UPOV. También puede asumirse que al menos algunos países de América Latina accederán a la Convención de la UPOV, muy probablemente al Acta de 1978, esto es, antes del 31 de diciembre de 1995, como está estipulado bajo el artículo 37(3) del Acta de 
Revisión de $1991^{81}$. Si una suscripción del Acta de la UPOV de 1978 o de 1991 es considerada más ventajosa para países con abundantes recursos genéticos, no puede ser aquí discutido en detalle. Deberá ponerse atención, sin embargo, al hecho de que el Acta de 1978 no garantiza protección para todos los géneros y especies botánicas, y bajo ninguna condición cubre productos finales ${ }^{82}$. Ambos aspectos pueden ser de particular interés para países que disponen de ricos recursos genéticos y exportan otros productos agrícolas. Además, contrariamente a una opinión defendida ocasionalmente ${ }^{83}$, la prohibición de la «doble protección», como existe bajo el Acta de 1978 de la UPOV, es una carga antes que una ventaja. Su remoción en el Acta de 1991 no significa más que la libertad de los Estados contratantes para permitir o no la doble protección. Como se ha indicado arriba, los países ricos en recursos genéticos deberían estar interesados en que los derechos de propiedad intelectual cubran toda la vasta extensión de inventos biotecnologicos, puesto que sólo tales derechos eventualmente les proveerán la recompensa adecuada a cambio del acceso a sus recursos genéticos.

Considerando las quejas frecuentes de que los derechos de propiedad industrial afectarían negativamente la diversidad biológica, parece necesario y a la vez suficiente llamar la atención sobre el hecho de:

«que los derechos y patentes de variedad de plantas son sólo la expresión de una alternativa fundamental basada esencialmente en un cierto número de consideraciones y razonamientos socioeconómicos, y que los estatutos que confieren estos derechos exclusivos son sólo instrumentos técnicos cuya configuración es dictada esencialmente por la especificidad de su objeto (en este caso la materia viva) y por la lógica de la economía de mercado. Cualquier decisión sobre el instrumento legal requiere

81 Ver las exposiciones de Ordóñez (Argentina) y Gutiérrez de la Roche (Colombia), N 1405 y 1406 de los Registros de la Conferencia Diplomática de Revisión de la UPOV, op. cit., nota al pie 14. Cf. también Correa, 1992 EIPR 157.

82 Hasta ahora, prácticamente ningún país ha aprovechado la posibilidad establecida bajo el artículo 5 (4) de la Convención de la UPOV, permitiendo a los Estados miembros extender protección también a los productos finales.

83 Cf. Correa, 1992 EIPR 157. 
una exposición clara del objetivo, esto es, $\mathrm{si}-\mathrm{y}$ hasta qué punto- los efectos de la diversidad biológica son (o no) admisibles tomando en cuenta los otros efectos de la protección de la innovación biológica a través de derechos de propiedad industrial exclusivos» ${ }^{84}$.

En otras palabras, el impacto de los derechos de propiedad intelectual sobre la diversidad biológica no puede ser juzgado adecuadamente en forma aislada. Más bien debe ser visto en el contexto de la cabal complejidad de una economía nacional determinada. Queda a discreción del legislador contrarrestar el uso excesivo de particulares variedades exitosas (estén protegidas o no), como por ejemplo prescribiendo para una u otra una reducida participación en los tipos de tierras que serán usadas en añadidura para las variedades nuevas - para las cuales, por ejemplo, subsidios y otros incentivos financieros podrían ser estipulados-, o dictando medidas de conservación in situ o ex situ (bancos de genes). En vista de experiencias pasadas, cada país debería estar en posición de evitar cautelosamente monocultivos vulnerables en su agricultura.

Desde el punto de vista del autor, tanto los países desarrollados como aquellos en vías de desarrollo deberían percatarse de que en un período de globalización de la investigación y el desarrollo, la producción y el comercio, que están basados predominantemente en la propiedad privada, el libre comercio o libre competencia, etc., así como en los principios de la economía de mercado, no puede ser negada la necesidad de que los derechos de propiedad intelectual en todos los países participantes en este proceso global, deben gozar de muy similares si no iguales niveles de protección. La libertad de los países para actuar dentro de sus fronteras, piedra angular del principio de trato nacional bajo la Convención de París, ha sido así limitada en relación a la extensión que se le ha dado en el proceso de globalización $^{85}$. Esto, sin embargo, no significa ni debe significar que el problema en cuestión siempre debería ser analizado bajo las negociaciones

84 Como ha sido correctamente observado por Bergmans, «Industrial Property and Biological Diversity of Plant and Animal Species» 72 JPTOS 601-609(609) (1990).

85 Ver Straus, «Industrial Property Legislation as an element in Market Economies», AIPPI Annuaire 1992/III, p. 324-336 (334). 
de los «aspectos relacionados al comercio» (TRIPs) al interior del Acuerdo General de Aranceles y Comercio (GATT). Mientras que es con seguridad verdadero que por elevar los niveles de protección de los derechos de propiedad intelectual sanciones comerciales, tales como pérdida de la posición de preferencia, imposición de derechos de aduana, etc., pueden ser evitadas, ello parece, sin embargo, completamente inapropiado para atribuir a tales efectos indirectos el único aspecto positivo de los derechos de propiedad intelectual en un país en vías de desarrollo ${ }^{86}$. Una evaluación responsable sobre si establecer o mejorar los derechos de propiedad intelectual en biotecnología, tiene que comenzar por analizar el estado actual de la investigación, el desarrollo y la producción en algún Estado determinado ${ }^{87}$. En una situación donde no hay o hay poca actividad en el campo de la biotecnología, bien sea por parte de compañías nacionales o extranjeras o por parte de organizaciones de investigación, parece, a lo más, vano afirmar que cualquier clase de protección será predominantemente o aun exclusivamente para el beneficio de compañías transnacionales ${ }^{88}$. El tema en cuestión es mucho más complejo y la pregunta a ser respondida es cómo incentivar mejor los intereses y usar el interés de, por ejemplo, compañías transnacionales y organizaciones de investigación del mundo desarrollado para el beneficio de la economía nacional de un Estado determinado. Es esencial notar que especialmente en agricultura los resultados de la investigación en biotecnología tienen que ser adaptados a las condiciones locales de clima y suelo. Así, la protección adecuada como estímulo para inversio-

86 Ésta parece ser la actitud predominante de Solleiro, «Patentes en biotecnología: oportunidades, amenazas y opciones para América Latina», en Biotecnología y patentes, Revista del Derecho Industrial, № 34 , enero-abril de 1990 , p. $107-135$ (122-123).

87 Parece ser irresponsable y populista continuar atacando los derechos de propiedad intelectual en lo que respecta a los países en vías de desarrollo, usando argumentos que han sido utilizados contra ellos en el pasado remoto, por ejemplo en Suiza y los Países Bajos durante la última parte del siglo XIX y aún después. Debe tomarse en cuenta que, por un lado, la situación global ha cambiado completamente y, por otro, la situación local es comparable sólo hasta cierto grado. Como estas consideraciones son soslayadas, siempre razonan de la manera aludida autores como Hobbelink, Biotechnology and the Future of World's Agriculture, Londres, 1991, p. 99 ss.

88 Cf. Solleiro, Revista del Derecho Industrial, $\mathrm{N}^{\circ} 34$, enero-abril de 1990, p. $108,128$. 
nes locales en desarrollo es requerida por el país mismo ${ }^{89}$. En este último contexto, la Convención de Biodiversidad, si es enmendada y revisada apropiadamente, podría ofrecer potenciales beneficios para todas las partes interesadas $^{90}$.

89 En realidad, en América Latina, en donde diversos programas nacionales e internacionales están dirigidos al fomento de la «biotecnologización» de la industria, más bien que al «mero» desarrollo de biotecnologías, la regulación de los derechos de propiedad intelectual a niveles internacionales está siendo progresivamente considerada como un prerrequisito para la participación en la economía global (cf. Commandeur, "Latin America commences to "biotechnologize" its industry", Biotechnology and Development Monitor 3-5 (marzo de 1993)). La actual carencia de adecuada protección para los inventos biotecnológicos en la India es también vista en parte como un obstáculo para el potencial de una autóctona industria biotecnológica hindú. Debido a esta situación, compañáas locales exitosas mantienen know kow secretos dentro del personal R \& D (ver Knudsen, «Unicorn Biotek: Indian Micropropagation to the World Market», Biotechnology and Development Monitor 10-11 (marzo de 1993)).

90 La advertencia dada por Juma, «Intellectual Property Rights for Biological Inventions", en Juma \& Ojwang (ed.), Innovation and Sovereignity. The Patent Debate in African Development, 145 s., en 170 (Nairobi, 1990), de que los países en vías de desarrollo deberían «investigar vías para introducir en su legislación medidas que puedan proteger a los innovadores locales y al mismo tiempo proteger a dichos países de los efectos de algunas de las reformas que están en boga en los países industrializados», parece una advertencia de doble filo. No toma en cuenta el proceso de globalización ni la necesidad omnipresente de las industrias locales de cooperar con socios extranjeros. 